\title{
APPLICATION OF REMOTE SENSING FOR TEMPERATURE MONITORING: THE TECHNIQUE FOR LAND SURFACE TEMPERATURE ANALYSIS
}

\author{
Teerawong Laosuwan ${ }^{1,2^{*}}$, Torsak Gomasathit ${ }^{1,2}$, Tanutdech Rotjanakusol ${ }^{1,2}$ \\ 1 Faculty of Science, Mahasarakham University, Katarawichai, Mahasarakham, 44150, Thailand \\ 2 Space Technology and Geoinformatics Research Unit, Faculty of Science, Mahasarakham University, \\ Mahasarakham, 44150, Thailand \\ * Corresponding author's e-mail: teerawong@msu.ac.th
}

Received: 2017.02.13

Accepted: 2017.03.07

Published: 2017.05.02

\begin{abstract}
This research aimed to present the technique for land surface temperature analysis with the data from Landsat-8 Operational Land Imager (OLI) /Thermal Infrared Sensors (TIR) in Meuang Maha Sarakham District, Maha Sarakham Province, Northeast Thailand. The research was conducted as following three steps: 1) Collecting the satellite data in thermal infrared band from Landsat- 8 TIR satellite to adjust the value of Top of Atmosphere (ToA) Reflectance and then analyzing the land surface temperature 2) Collecting multi-band data from Landsat-8 OLI satellite to adjust the value of Top of Atmosphere (ToA) Reflectance and then analyzing values of Normalized Difference Vegetation Index (NDVI), Fractional Vegetation Cover (FVC) and Land surface Emissivity (LSE) 3) Bringing the results of 1) and 2) to analyze the land surface temperature with split window algorithm. The research results indicated that the analysis of the data from Landsat-8 OLI/TIR satellites in 18 March 2015 indicated a mean temperature of $33.57^{\circ} \mathrm{C}$.
\end{abstract}

Keywords: Remote Sensing, Landsat-8 OLI/TIR data, Land Surface Temperature

\section{INTRODUCTION}

Currently, urban areas have been developed as a result of economic growth. This results in changes in land use. Also, many areas have been developed, modified and changed in order to support creation of economic areas. The original areas including agricultural areas and empty areas were replaced by public infrastructures, such as buildings, streets, etc. [Wanpen, 2012].

The original areas that were surfaces with good absorption and humidity, such as plants, soils and water resources, were changed to surfaces containing concrete and asphalt. It contributed to the increase of solar heat absorption on the surfaces in urban areas which could absorb the heat during daytime more than natural surfaces. Also, they were mostly green spaces and agricultural areas. During nighttime, the surfaces in urban areas will release the accumulated heat energy during daytime into the atmosphere in a higher amount than natural surfaces. The surfaces in urban areas will accelerate moisture evaporation more than natural surfaces with a better property of moisture absorption. As a result, the temperatures in urban areas will be higher compared to surrounding rural areas [Taha, 1997; Watkins, 1999; Liang, 2004; Zhou et al., 2011].

The different temperatures cause formation of Urban Heat Island (UHI) phenomenon, which air temperatures during daytime of a big city may be higher than surrounding areas up to $1-3^{\circ} \mathrm{C}$ [David et al., 2011] during nighttime. The difference of temperatures can be up to $12^{\circ} \mathrm{C}$ in a city or a small community with a less number of population. The consequences of the Urban Heat Island phenomenon will decrease in accordance with a less number of populations. Many researches indicated wide acceptances on a relationship between temperatures and land cover by indicating that 
the temperatures of green spaces will be lower than areas with buildings [Kimura and Takahashi, 1991; Asaeda et al, 1996; Svensson and Eliasson, 2002; Wong and $\mathrm{Yu}, 2005]$.

In Thailand in the year 2015, the average yearly temperature was higher than the normal temperature of $0.8^{\circ} \mathrm{C}$ and higher than the temperature of the previous year $\left[0.4^{\circ} \mathrm{C}\right.$ higher than the normal temperature in 2014]. Many areas had the highest temperatures which were higher than the previous measured records. The average monthly temperatures were higher than every normal monthly temperature, especially November and December which had higher temperatures than $2.1^{\circ} \mathrm{C}$ and $1.9^{\circ} \mathrm{C}$, respectively [Thai Meteorological Department, 2015].

Nonetheless, the research on the influence of land cover affecting temperatures in the atmosphere of Bangkok was conducted by applying data from Landsat $5 \mathrm{TM}$ satellite. The research found that if there was an increase of trees for 1 percent in an area of 0.1 square kilometers $\left(\mathrm{km}^{2}\right)$, the temperature will decrease at $0.028^{\circ} \mathrm{C}$. Therefore, there should have a change of proportion of land cover by allocating green spaces and water resources properly [Wanpen, 2012].

The application of remote sensing technology in the study of land use and land cover by data from earth observation satellites, namely Landsat $5 \mathrm{TM}$, Landsat $7 \mathrm{ETM}+$ and Landsat $8 \mathrm{OLI} / \mathrm{TIR}$, was conducted in order to study wide areas and to monitor changes in land use and land cover quickly [Campbell, 1996; Teerawong and Pornchai, 2014; Szymon et al., 2015; Yannawut and Teerawong; 2016; Laosuwan et al., 2016; Teerawong and Yannawut, 2016; Yannawut and Teerawong, 2017].
Generally, the data from the satellites in visible band and infrared band were mainly used. These satellites had a session of repeated record that was proper for applying the data. Also, they could almost monitor situations of land use and land cover in a real time. Moreover, they could analyze the land surface temperature by using thermal infrared band. From the importance of increasing of such the temperatures, this study aimed to present the technique for land surface temperature analysis by the data from Landsat-8 OLI/ TIR satellites in Meuang Maha Sarakham District, Maha Sarakham Province, Northeast Thailand.

\section{MATERIALS AND METHODS}

\section{The study area and data collection}

Meuang Maha Sarakham District with an area of $556.70 \mathrm{~km}^{2}$ is the capital district of Maha Sarakham Province, Northeast Thailand. Meuang Maha Sarakham District is divided into 14 subdistricts as follows; Talat, Khwao, Tha Tum, Waeng Nang, Khok Ko, Don Wan, Koeng, Kaeng Loeng Chan, Tha Song Khon, Lat Phatthana, Nong Pling, Huai Aeng, Nong No and Bua Kho.

For data collection from the satellites in this study, the researchers had collected the data from Landsat-8 OLI/TIR satellites (level $1 \mathrm{G}$ product) in path 127 Row 49 on 18 March 2015 as following details:

1. The data of thermal infrared band for Landsat- 8 TIR used Band 10 and Band 11

2. The data of multi-band for Landsat- 8 OLI used Band 3, 4, 5

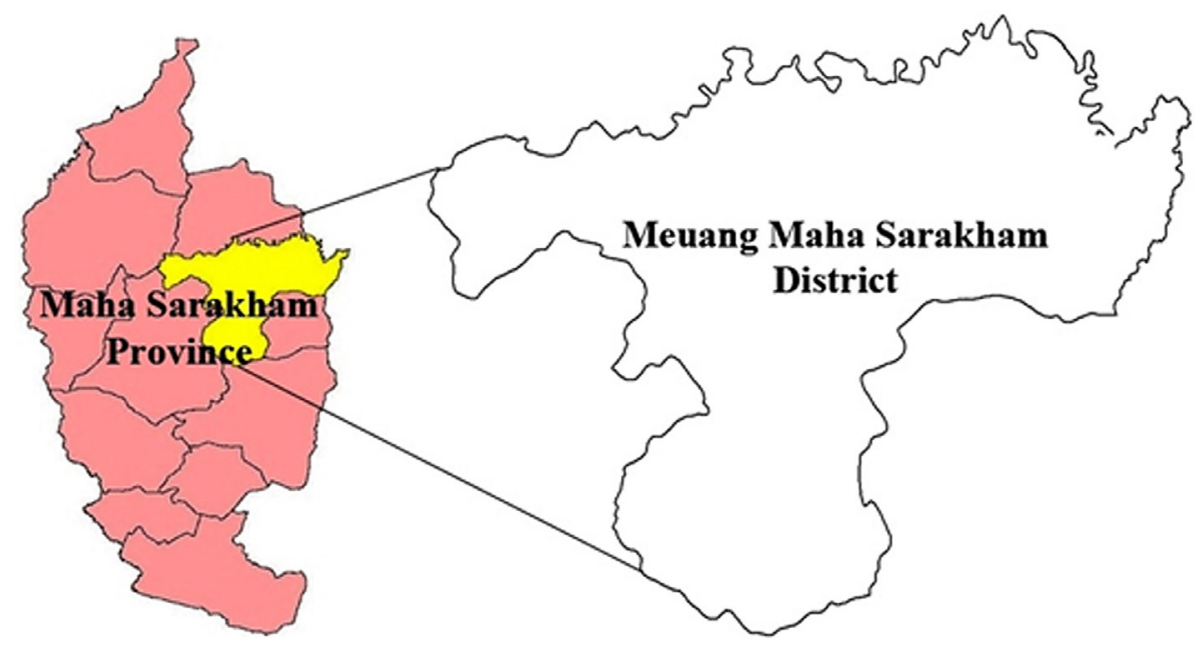

Figure 1. Meuang Maha Sarakham District 


\section{Implementation in Landsat-8 TIR}

Correcting the value of Top of Atmosphere (ToA) Reflectance in infrared Band 10 and Band 11 of Landsat-8 TIR to reduce errors of the energy reflected from objects on the earth's surfaces to the data recorder from surrounding environment while recording data, including weather, topography, temperature and angle of incidence by Equation 1 [Barsi et al., 2014; Rajeshwari and Mani, 2014]

$$
L_{\lambda}=M_{L} * Q c a l+A_{L}
$$

where: $L_{\lambda}=$ Top of Atmosphere spectral radiance $\left[\mathrm{W} /\left(\mathrm{m}^{2} \mathrm{sr} \mu \mathrm{m}\right)\right]$

$M_{L}=$ Band specific multiplicative rescaling factor (Table 1)

Qcal $=$ OLI/TIR image

$A_{L}=$ Band specific additive rescaling factor (Table 1)

Analyzing absolute temperature from band radiation of the data from Landsat- 8 TIR in this study was conducted by Equation 2 [Shaohua et al., 2009; USGS, 2013; Rajeshwari and Mani, 2014; Ugur and Gordana, 2016].

$$
T_{B}=\frac{k_{2}}{\ln \left[\left[k_{1} / L_{\lambda}\right]+1\right]}
$$

where: $k_{1}$ and $k_{2}=$ Thermal conversion constant for TIR band (Table 2)

$L_{\lambda}=$ Top of Atmosphere spectral radiance

For finding the results in Celsius $\left({ }^{\circ} \mathrm{C}\right)$, the absolute temperature is revised by adding the absolute zero (approximately $-273.15^{\circ} \mathrm{C}$ ) $[\mathrm{Xu}$ and Chen, 2004; USGS, 2013]

\section{Implementation in Landsat-8 OLI}

Correcting the value of Top of Atmosphere (ToA) Reflectance in multi-band of Landsat-8 OLI to reduce errors of the energy reflected from objects on the earth's surfaces to the data recorder from surrounding environment while recording data, including weather, topography, temperature and angle of incidence by Equation 1 .

\section{Analysis of NDVI, FVC and LSE}

Normalized Difference Vegetation Index (NDVI): The analysis of NDVI was conducted from the ratio of difference and sum total of reflection of visible light band, red band and near infrared band from objects on the earth's surfaces. The result of the calculation was an index be-
Table 1. Rescaling factor [Skokovic, et al., 2014; Ugur and Gordana, 2016]

\begin{tabular}{|c|c|c|}
\hline Rescaling factor & Band 10 & Band 11 \\
\hline$M_{L}$ & 0.000342 & 0.000342 \\
\hline$A_{L}$ & 0.1 & 0.1 \\
\hline
\end{tabular}

Table 2. Thermal constant [Rajeshwari and Mani, 2014; Ugur and Gordana, 2016].

\begin{tabular}{|c|c|c|}
\hline Thermal Constant & Band 10 & Band 11 \\
\hline$k_{1}$ & 1321.08 & 1201.14 \\
\hline$k_{2}$ & 777.89 & 480.89 \\
\hline
\end{tabular}

tween -1 and +1 . The NDVI of water surface was less than 0 . The NDVI of bare ground as between $0-0.1$ and the NDVI of the ground with plants covered was over 0.1 . The analyses of NDVI in this study were conducted by Equation 3 [Yannawut and Teerawong, 2016].

$$
N D V I=\frac{N I R-R E D}{N I R+R E D}
$$

where: $N I R=$ Near infrared band of Landsat 8 OLI

$R=$ Red band of Landsat 8 OLI

Fractional Vegetation Cover (FVC): For the analysis of Fractional Vegetation Cover in this study, the NDVI data from the analysis above was used to determine the NDVI for soil at 0.2 and NDVI for vegetation at 0.5 . The analysis was conducted by Equation 4 [Shahid, 2014; Rajeshwari and Mani, 2014; Ugur and Gordana, 2016].

$$
F V C=\frac{N D V I-N D V I_{s}}{N D V I_{V}+N D V I_{s}}
$$

where: $N D V I=$ NDVI of mixed pixel

$N D V I_{V}=\mathrm{NDVI}$ of vegetation

$N D V I_{S}=\mathrm{NDVI}$ of soil

Land Surface Emissivity (LSE): This study used the FVC data to analyze by Equation 5 [Rajeshwari and Mani, 2014]. The constants of Band10 were emissivity for soil of 0.971 and emissivity for vegetation of 0.987 . The constants of the Band11 were emissivity for soil of 0.977 and emissivity for vegetation of (0.989).

$$
L S E=\varepsilon_{s}(1-F V C)+\varepsilon_{V} * F V C
$$

where: $\varepsilon_{s}$ and $\varepsilon_{V}=$ soil and vegetative emissivity values of the corresponding bands (see in table 3). 
Table 3. The emissivity Values [Skokovic, et al., 2014]

\begin{tabular}{|c|c|c|}
\hline Emissivity & Band 10 & Band 11 \\
\hline $\boldsymbol{E}_{S}$ & 0.971 & 0.977 \\
\hline $\boldsymbol{E}_{V}$ & 0.987 & 0.989 \\
\hline
\end{tabular}

\section{Land Surface temperature analysis with Split Window Algorithm}

The land surface temperature analysis with Split Window Algorithm in this study was conducted in three stages as follows: 1) Analysis of mean by Equation 6, 2) Analysis of difference by Equation 7 and 3) Analysis of land surface temperature by Equation 8 and Table 4 as following details: [François and Zhao, 1990; Rajeshwari and Mani, 2014; Fei et al., 2015; Julie et al., 2015; Ugur and Gordana, 2016].

$$
\begin{aligned}
& \text { Mean_of_LSE }=m=\frac{L S E 10+L S E 11}{2} \\
& \text { Difference_of_LSE }=\Delta m=L S E 10-L S E 11 \\
& L S T=T B 10+C 1(T B 10-T B 11)+C 2(T B 10-T B 11)^{2}+ \\
& C 0+(C 3+C 4 W)(1-m)+(C 5+C 6 W) \Delta m
\end{aligned}
$$

Table 4. The Split Window coefficients value [Rajeshwari and Mani, 2014]

\begin{tabular}{|c|c|}
\hline Constant & Value \\
\hline C0 & -0.268 \\
\hline C1 & 1.378 \\
\hline C2 & 0.183 \\
\hline C3 & 54.300 \\
\hline C4 & -2.238 \\
\hline C5 & -129.200 \\
\hline C6 & 16.400 \\
\hline
\end{tabular}

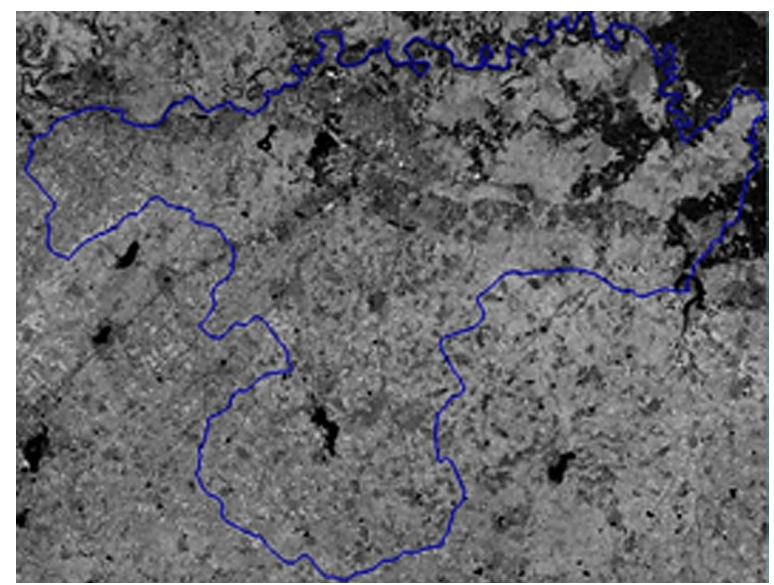

Figure 2. For example Band 10 Before TOA where: $T B 10$ and $T B 11=$ Brightness Temperature of Band 10, 11

$$
\begin{aligned}
& C 0-C 9=\text { Split-Window coefficient } \\
& \text { values } \\
& m=\text { Mean } L S E \\
& \Delta m=\text { Difference of } L S E \\
& W=\text { Atmospheric water-vapour content }
\end{aligned}
$$

\section{RESULTS}

\section{The results of implementation in infrared band}

The results of operations of adjusting the value of Top of Atmosphere (ToA) Reflectance in infrared Band 10 and Band 11 of Landsat- 8 TIR to reduce errors of the energy reflected from objects on the earth's surfaces to the data recorder from surrounding environment while recording data can be shown in Figure 2 and Figure 3. The analysis results of the absolute temperature from the band radiation of data of Landsat- 8 TIR can be shown in Figure 4 and Figure 5.

\section{The results of implementation in multi-band band}

The results of operations of adjusting the value of Top of Atmosphere (ToA) Reflectance in multi-band of Landsat-8 OLI to reduce errors of the energy reflected from objects on the earth's surfaces to the data recorder from surrounding environment while recording data can be shown in Figure 6 and Figure 7.

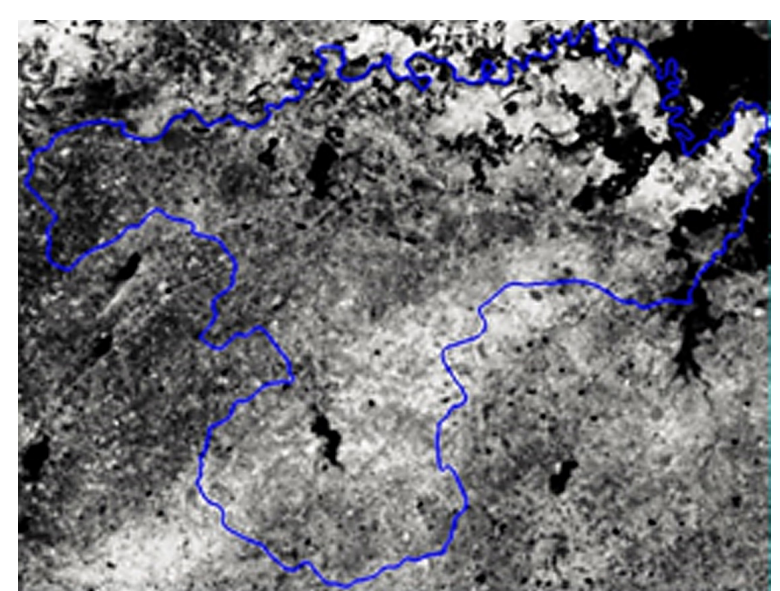

Figure 3. For example Band 10 After TOA 


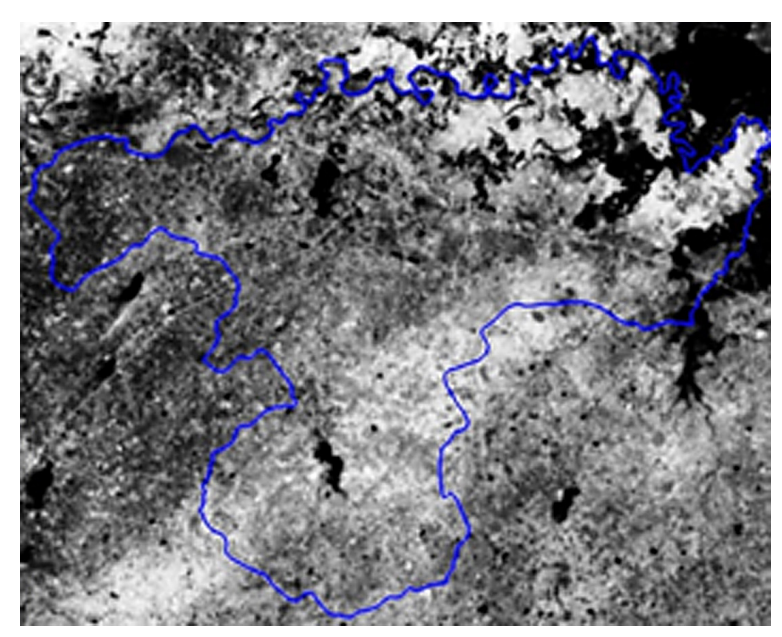

Figure 4. Display absolute temperature

The analysis results of NDVI from finding the ratio between difference and sum total of the reflection of visible light band, red band and near infrared band from objects on the earth's surfaces. The result of the calculation was a minimum of NDVI at - 1.00, a maximum of NDVI at 0.94 , a mean of 0.38 and StdDev of 0.21 .

The analysis results of Fractional Vegetation Cover in this study used NDVI from the analysis above to determine the NDVI for soil of 0.2 and NDVI for vegetation of 0.5 . The results of the study indicated a minimum of -4.00 , a maximum of 2.46, a mean of 0.61 and StdDev of 0.68.

The analysis results of LSE data were analyzed by analyzing FVC data and determining the constants of Band 10 which consisted of Emissivity for Soil of 0.971 and Emissivity for Vegetation of 0.987 . The constants of the Band 11 consisted of Emissivity for Soil of 0.977 and Emissivity for Vegetation of 0.989 . The study results of Band 10 indicated a minimum of 1.32 , maximum of 1.59 , mean of 1.46 and StdDev of 0.03. Meanwhile, the study results from Band 11 were found a minimum of 1.21 , a maximum of 1.40 , a mean of 1.32 , and StdDev of 0.02.

\section{The analysis results of the surface temperature with Split Window Algorithm}

The analysis results of the surface temperature with Split Window Algorithm in this study were conducted in three phases: 1) Analysis of mean by Equation 6, 2) Analysis of difference by Equation 7, and 3) Analysis of land surface temperature by Equation 8. The results in sub-districts level of this study can be shown in Table 5 and the result of Meuang Maha Sarakham District was shown in Figure 8 and Table 6.

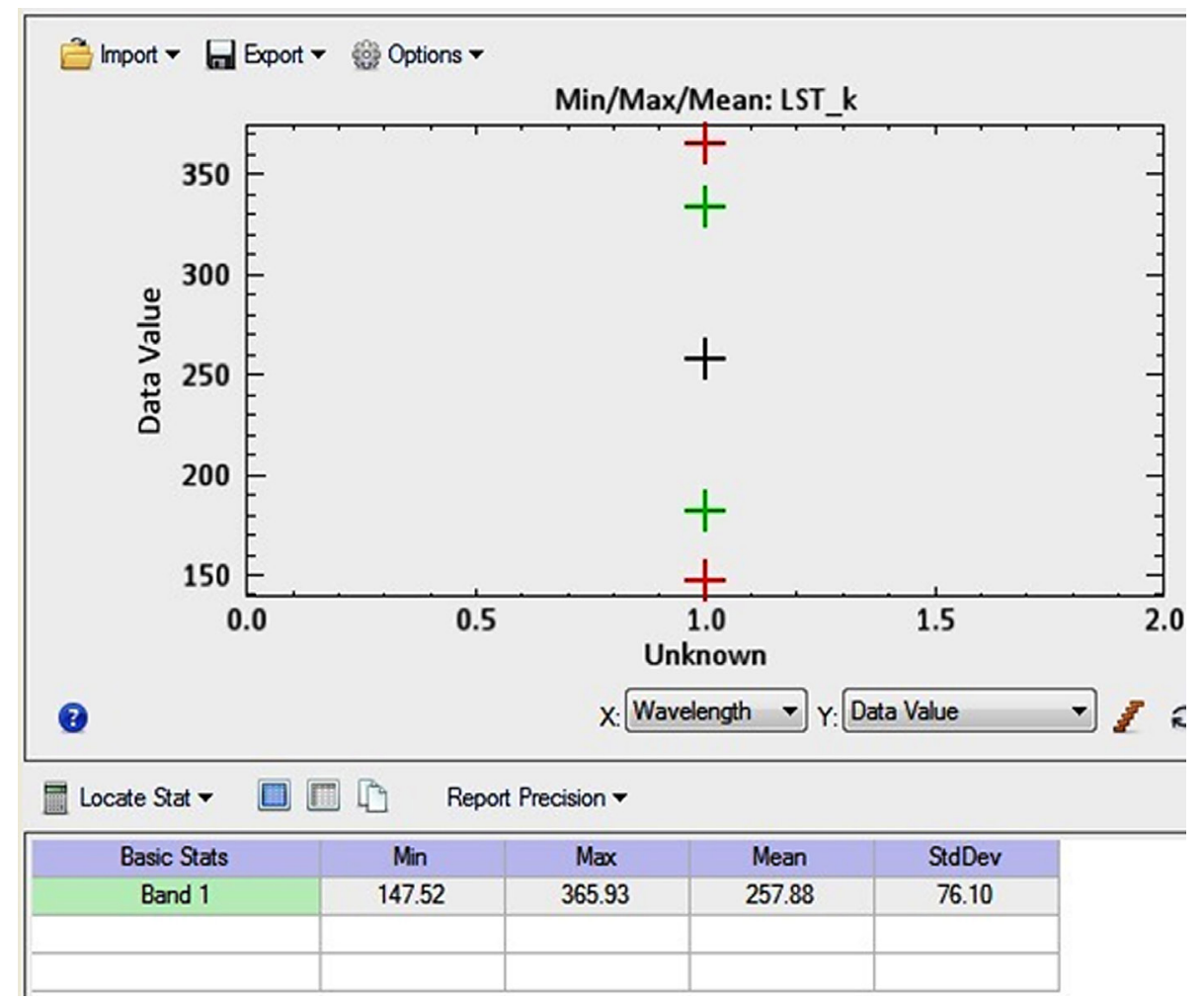

Figure 5. Compute statistics data in Kelvin 


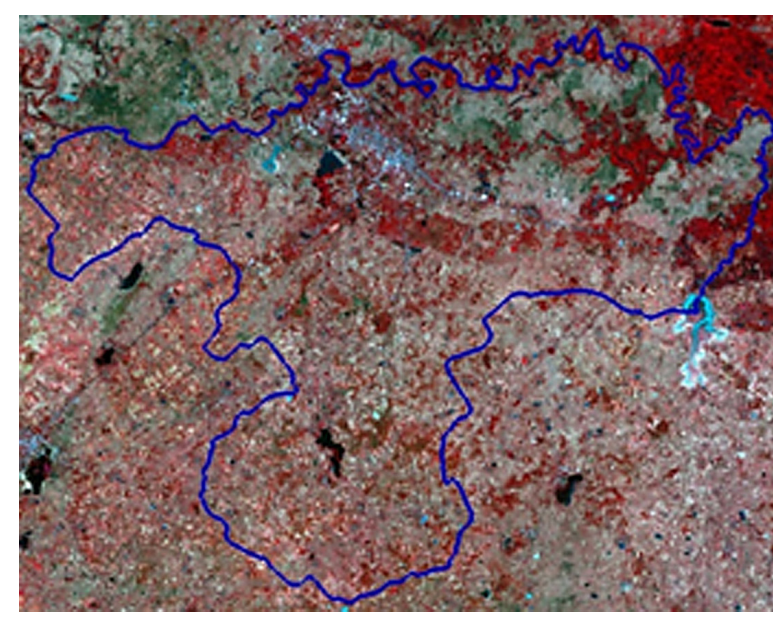

Figure 6. Before TOA

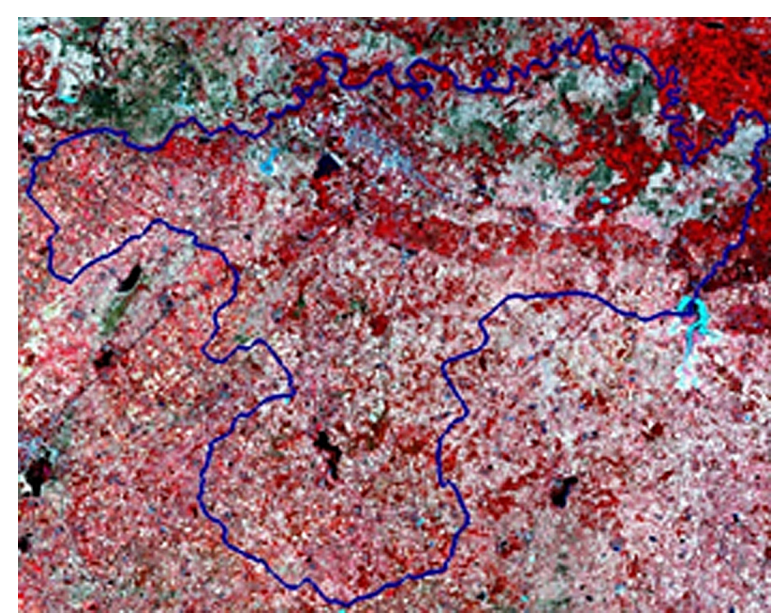

Figure 7. After TOA

Table 5. The analysis results of the surface temperature in sub-districts level

\begin{tabular}{|c|l|c|c|c|c|}
\hline \multirow{2}{*}{ Satellite Data } & \multicolumn{1}{|c|}{ Sub-districts } & \multicolumn{4}{c|}{ Temperature $\left({ }^{\circ} \mathrm{C}\right)$} \\
\cline { 2 - 6 } & & Min & Max & Mean & StdDev \\
\hline \multirow{5}{*}{$\begin{array}{c}\text { Landsat-8 OLI/TIR } \\
\text { acquired on 18 March } \\
2015\end{array}$} & Khok Ko & 22.83 & 32.27 & 27.31 & 2.30 \\
\cline { 2 - 6 } & Tha Song Khon & 25.45 & 33.41 & 28.56 & 0.89 \\
\cline { 2 - 6 } & Waeng Nang & 25.02 & 29.29 & 27.62 & 0.88 \\
\cline { 2 - 6 } & Kaeng Loeng Chan & 23.71 & 31.37 & 28.57 & 0.99 \\
\cline { 2 - 6 } & Bua Kho & 33.60 & 41.10 & 37.67 & 0.97 \\
\cline { 2 - 6 } & Don Wan & 30.64 & 40.99 & 36.94 & 1.20 \\
\cline { 2 - 6 } & Huai Aeng & 32.07 & 38.58 & 35.61 & 1.34 \\
\cline { 2 - 6 } & Koeng & 29.59 & 38.48 & 33.92 & 1.77 \\
\cline { 2 - 6 } & Khwao & 28.21 & 38.73 & 33.75 & 3.87 \\
\cline { 2 - 6 } & Lat Phatthana & 29.83 & 41.31 & 36.03 & 1.11 \\
\cline { 2 - 6 } & Nong No & 33.94 & 39.36 & 36.81 & 1.06 \\
\cline { 2 - 6 } & Nong Pling & 29.07 & 40.17 & 37.51 & 3.23 \\
\cline { 2 - 6 } & Talat & 30.57 & 40.32 & 35.92 & 2.01 \\
\cline { 2 - 6 } & Tha Tum & & & & \\
\hline
\end{tabular}

Table 6. The analysis results of the surface temperature in Meuang Maha Sarakham District

\begin{tabular}{|c|c|c|}
\hline $\begin{array}{c}\text { Temperature } \\
\text { classification }\left({ }^{\circ} \mathrm{C}\right)\end{array}$ & Areas $\left(\mathrm{km}^{2}\right)$ & Percent $(\%)$ \\
\hline $0-7$ & 26.52 & 4.62 \\
\hline $8-14$ & 44.73 & 7.80 \\
\hline $15-21$ & 91.76 & 16.00 \\
\hline $22-28$ & 131.47 & 24.85 \\
\hline $29-35$ & 165.99 & 30.29 \\
\hline $36-42$ & 96.23 & 16.44 \\
\hline Result & 556.70 & 100 \\
\hline
\end{tabular}

\section{CONCLUSSIONS}

This research had presented the technique for land surface temperature analysis with the data from Landsat-8 OLI/TIR satellites in Meuang Maha Sarakham District in 18 March 2015. It could be found a mean temperature of $33.57^{\circ} \mathrm{C}$.
Meanwhile, the land surface temperature data from Thai Meteorological Department indicated a mean temperature measured of $33.11^{\circ} \mathrm{C}$. When statistically compared the analysis of land surface temperature with the data from satellites and data measured by Thai Meteorological Department with Pair Sample T-test, it showed no statistically significant difference at a confidence level of $95 \%$. At any rate, the researchers will keep applying the technique for surface temperature analysis with the data from the satellites in analysis of relationship between urban heat island and urban physical environment of Meuang Maha Sarakham District, Maha Sarakham Province onwards.

\section{Acknowledgements}

This research was financially supported by Mahasarakham University, 2017. 

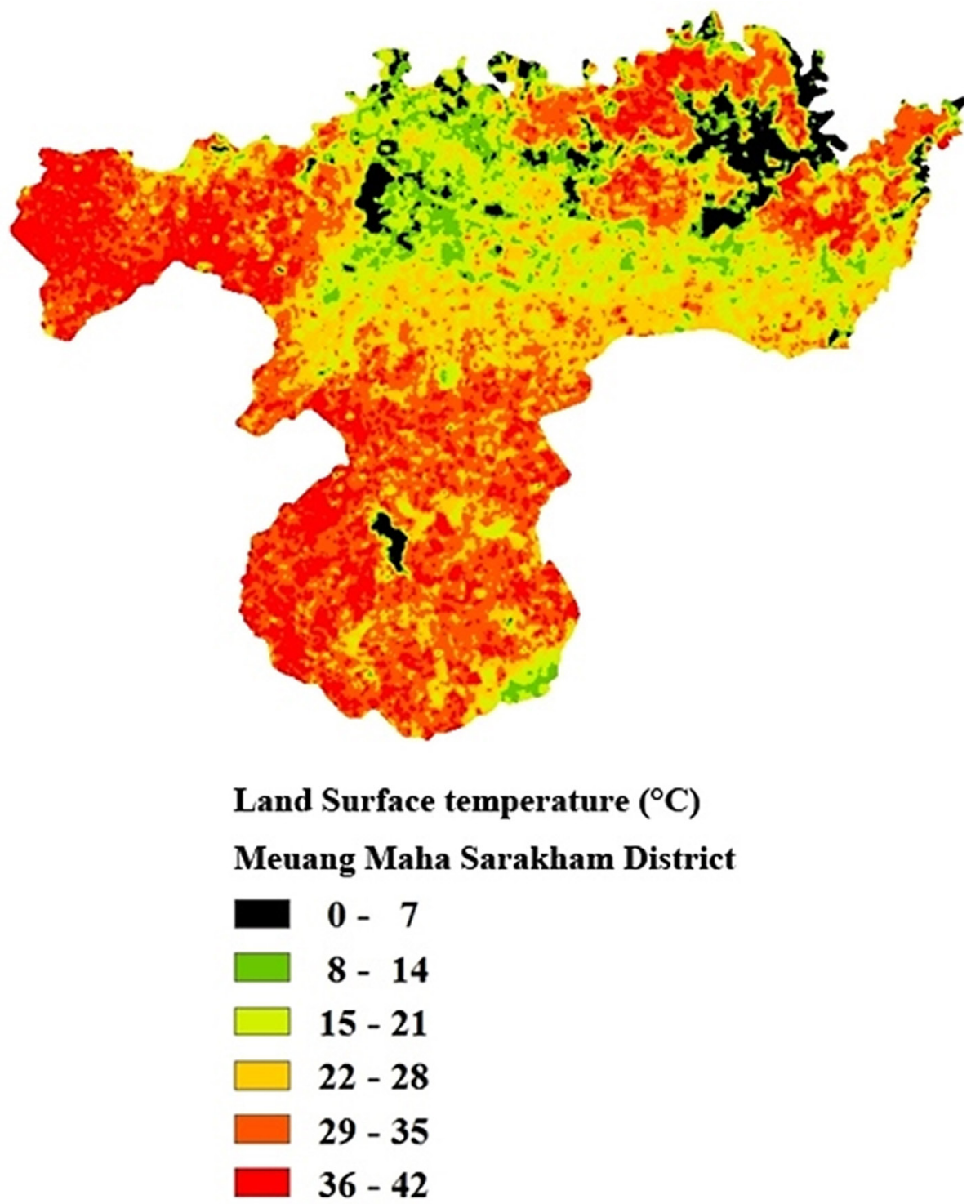

Figure 8. Land surface temperature in Meuang Maha Sarakham District

\section{REFERENCES}

1. Asaeda, T., Ca, V.T., and Wake, A. 1996. Heat Storage of Pavement and its Effect on the Lower Atmosphere. Atmospheric Environment, 30 (3), 413-427.

2. Barsi, J.A., Schott, J.R., Hook, S.J., Raqueno, N.G., Markham, B.L., and Radocinski, R.G. 2014. Landsat-8 thermal infrared sensor (TIRS) vicarious radiometric calibration. Remote Sensing, 6 (11), 11607-11626.

3. Campbell, J.B. 1996. Introduction to Remote Sensing. Taylor \& Francis, London.

4. David Cole, Nikolaas Dietsch, Gary Gero, David Hitchcock, Megan Lewis, Eliasson, I. 1996. Urban noctural temperatures, street geometry and land use. Atmospheric Environment, 30 (3), 379-392.

5. François Becker and Zhao-Liang Li. 1990. Towards a local split window method over and sur- faces. International Journal of Remote Sensing, 11 (3), 369-393.

6. Fei Wang, Zhihao Qin, Caiying Song, Lili Tu, Arnon Karnieli and Shuhe Zhao. 2015. An improved mono-window algorithm for land surface temperature retrieval from landsat 8 thermal infrared sensor data. Remote Sensing, 7 (4), 4268-4289.

7. Julie Magee, Misha Sarkovich, Jim Yarbrough, and Barry Zalph. 2015. Reducing Urban Heat Islands: Compendium of Strategies Heat Island Reduction Activities. https:/www.epa.gov/sites/production/ files/2014-06/documents/activitiescompendium. pdf [access 02/02/2015].

8. Kimura, F., Takahashi, S. 1991. The effects of landuse and anthropogenic heating on the surface temperature in the Tokyo metropolitan area: a numerical experiment. Atmospheric Environment, 25 (2), 155-164.

9. Liang, S. 2004. Quantitative remote sensing of 
land surface, New Jersey, Wiley: Interscience.

10. Laosuwan, T., Sangpradid, S., Gomasathit, T. and Rotjanakusol, T. 2016. Application of Remote Sensing Technology for Drought Monitoring in Mahasarakham Province, Thailand. International Journal of Geoinformatics, 12 (3), 17-25.

11. Rajeshwari, A. and Mani, N.D. 2014. Estimation of Land Surface Temperature of Dindigul District using Landsat 8 Data. International Journal of Research in Engineering and Technology, 3 (5), 122-126.

12. Shahid Latif. 2014. Land Surface Temperature Retrival of Landsat-8 Data Using Split Window Algorithm- A Case Study of Ranchi District. International Journal of Engineering Development and Research, 2 (4), 2840-3849.

13. Shaohua Zhao, Qiming Qin, Yonghui Yang, Yujiu Xiong and Guoyu Qiu. 2009. Comparison of two split-window methods for retrieving land surface temperature from MODIS data. Journal of Earth Syst. Science, 118 (4), 345-353.

14. Svensson, M.K. \& Eliasson, I.E. 2002. Diurnal air temperatures in built-up areas in relation to urban planning. Landscape and Urban Planning, 61 (1): 37-54.

15. Szymon Szewrański, Jan Kazak, Marta Szkaradkiewicz, Józef Sasik. 2015. Flood risk factors in suburban area in the context of climate change adaptation policies - Case study of Wroclaw, Poland. Journal of Ecological Engineering, 16 (2), 13-18.

16. Taha, H. 1997. Urban climates and heat islands: Albedo, evapotranspiration, and anthropogenic heat. Energy and Buildings, 25 (2), 99-103.

17. Teerawong Laosuwan and Pornchai Uttaruk. 2014. Estimating Tree Biomass via Remote Sensing, MSAVI 2, and Fractional Cover Model. IETE Technical Review, 31(5), 362-368.

18. Teerawong Laosuwan and Yannawut Uttaruk. 2016. Estimating Above Ground Carbon Capture using Remote Sensing Technology in Small Scale Agroforestry Areas, Agriculture and Forestry, 62
(2), 253-262.

19. Thai Meteorological Department. 2015. Weather Warning. https://www.tmd.go.th/en/index.php [access 07/03/2015].

20. Ugur Avdan and Gordana Jovanovska. 2016. Algorithm for Automated Mapping of Land Surface Temperature Using LANDSAT 8 Satellite Data. Journal of Sensors. Article ID 1480307, 1-8.

21. USGS. 2013. Using the USGS Landsat 8 Product http://landsat.usgs.gov/Landsat8UsingProduct.php [access 01/05/2013].

22. Wanpen Charoentrakulpeeti. 2012. Impact of Land Cover on Atmospheric Temperature in Bangkok. NIDA Journal of Environmental Management, $8(1), 1-18$.

23. Watkins, R. 1999. The impact of the urban environment on the energy demand for cooling buildings. Unpublished report, Brunel University and the Building Research Establishment Ltd.

24. Wong, N.H. and Yu, C. 2005. Study of green areas and urban heat island in a tropical city. Habitat International, 29 (3), 547-558.

25. Xu, H.Q. and Chen, B.Q. 2004. Remote sensing of the urban heat island and its changes in Xiamen City of SE China. Journal of Environmental Sciences. 16 (2), 276-281.

26. Yannawut Uttaruk and Teerawong Laosuwan. 2016. Remote sensing based vegetation indices for estimating above ground carbon sequestration in orchards. Agriculture and Forestry, 62 (4), 193-201.

27. Yannawut Uttaruk and Teerawong Laosuwan. 2017. Carbon Sequestration Assessment of the Orchards Using Satellite Data. Journal of Ecological Engineering, 18 (1), 11-17.

28. Zhou, J., Chen, Y.H., Wang, J.F., Zhan, W.F. 2011. Maximum nighttime urban heat island (UHI) intensity simulation by integrating remotely sensed data and meteorological observations. IEEE J. Sel. Top. Appl. Earth Observ, 4, 138-146. 